\title{
HOMEWORK IN THE CURRICULAR AREA OF MATHEMATICS IN PRIMARY EDUCATION
}

\author{
Fabiana Lopes (a), Ana Paula Cardoso (b)*, Luís Menezes (c), Ana Lopes (d) \\ *Corresponding author
}

\author{
(a) Instituto Politécnico de Viseu, CI\&DETS, Escola Superior de Educação, Viseu, Portugal, \\ fabiana.sousa.lopes@hotmail.com \\ (b) Instituto Politécnico de Viseu, CI\&DETS, Escola Superior de Educação, Viseu, Portugal, \\ a.p.cardoso62@gmail.com \\ (c) Instituto Politécnico de Viseu, CI\&DETS, Escola Superior de Educação, Viseu, Portugal, menezes@esev.ipv.pt \\ (d) Instituto Politécnico de Viseu, CI\&DETS, Escola Superior de Educação, Viseu, Portugal, \\ anacostalopes@esev.ipv.pt
}

\begin{abstract}
The present study aims to identify the perspectives of pupils and their parents/guardians related to homework in the curricular area of mathematics and how they are implemented. A study was developed using a descriptive research, resorting to various techniques of data collection: a questionnaire for the pupils, an interview to the parents/guardians and documentary research of teachers' homework records. The study involved fifty students of two 4th grade classes of a Portuguese primary school, aged from 9 to 11 years old of both sexes, four parents/guardians of these students and two teachers. Homework is a widespread practice in both classes under study, being part of the daily life of pupils and their families. The type of homework most often requested in the area of Mathematics consists of worksheets that involve algorithmic calculation and some problem solving. Parents are actively involved in supporting their children's homework, despite the difficulties they experience in such support. Homework represents a pedagogical strategy that is quite common, but seldom a target of reflection. It is important for teachers to reflect on the usefulness, type and extent of homework requested, as well as on student queries and parents' difficulties in supporting its fulfilment, so that it can be a true complement to classroom learning for all pupils.
\end{abstract}

(C) 2019 Published by Future Academy www.FutureAcademy.org.UK

Keywords: Homework, primary education, Mathematics. 


\section{Introduction}

Homework is one of the most popular educational strategies, but also one of the most controversial, used in virtually all levels of education (Cooper, Robinson, \& Patall, 2006; Fan, Xu, Cai, He, \& Fan, 2017; Menezes, Viseu, \& Conceição, 2016).

Homework can be defined as any academic work assigned at school by the teacher, but that is carried out by students during nonschool hours, usually at home and, therefore, without the teacher's direct guidance and monitoring (s)he usually gives students while they are performing the assigned tasks (Cooper, 2001; Cooper et al., 2006; Núñez, Suárez, Rosário, Vallejo, Valle, \& Epstein, 2015).

Homework is therefore a set of tasks intended for students to have additional learning opportunities outside the school (Silva, 2009). In the same sense, Marques (2001) argues that homework is an instrument that helps to strengthen and deepen student' learning. Some authors also consider that completing their homework can be a good way for students to learn how to manage time, to strengthen their sense of responsibility, and also to value effort and perseverance as a means of achieving their objectives (Epstein \& Van Voorhis, 2001). These authors also hold that the completion of homework can lead students to develop their autonomy in the use of didactic resources and help them acknowledge when the time is right to ask for help in view of difficulties they cannot overcome by themselves.

On the other hand, several authors are quite skeptical or critical of the effectiveness of homework (Fan et al., 2017; Perrenoud, 2010). These authors argue that homework represents a work overload for students, that most of those tasks are useless and have no significant learning gains (Perrenoud, 2010). In addition, homework can force parents to become tutors and make them feel incompetent because they cannot or are not able to help (Menezes et al., 2016; Perrenoud, 2010). Although some authors point out that homework is a means to improve the learning of students who have greater learning difficulties, by promoting compensation activities outside their school, Rønning (2011) reveals that, for the elementary education students he was given the opportunity to observe, homework contributed to the increase of social inequalities since children who came from disadvantaged socio-economic backgrounds were hampered by the lack of school support provided by their parents.

Over the last few years, meta-analyses of research on the educational value of homework have been carried out. Works like "Does homework improve academic achievement? A synthesis of research, 1987 2003" (Cooper et al., 2006) and "Homework and students' achievement in math and science: A 30-year meta-analysis" (Fan et al., 2017) are good examples of that concern. The first study focuses on homework in general and the second focuses on homework in mathematics and science. The study of Cooper et al. (2006) reveals a consistent evidence for a positive influence of homework on student achievement. The work of Fan et al. (2017) was conducted to understand the homework-achievement relationship in mathematics/science, and to find out other factors that could influence this relationship. This study reveals "that there was an overall small and positive relationship between homework and academic achievement in math/science (...). The homework-achievement relationship in math/science was stronger for elementary and high school students than for middle school students" (p. 35).

The involvement of parents/tutors in their children's education is essential so that students can achieve educational success. Although parents and teachers play different roles, they are complementary (Sheldon \& Epstein, 2005). Parents usually take an active part in their children's study by motivating their 
work and encouraging them to study, by organizing a timetable and creating conditions that will favour their work (Hagger, Sultan, Hardcastle, \& Chatzisarantis, 2015; Menezes et al., 2016).

When they were asked to give their opinion about mathematics homework, the parents' reactions were quite different. Many adults, for whom mathematics classes were a painful experience, have no positive recollections of the kind of tasks they were assigned (Aharoni, 2008; Menezes et al., 2016). Thus, a student who struggles with his math learning and who shows difficulties to apprehend what the teacher is trying to teach him will need his parents' support and encouragement to feel motivated to keep on working to overcome his difficulties. Therefore, it is essential for parents to be informed about how students are currently taught and how they can support their carrying out this work (Aharoni, 2008; Jay, Rose, \& Simmons, 2018; Menezes et al., 2016).

In the research conducted with the parents of 4th grade students, Menezes et al. (2016) point out that, when they help their children with their mathematics homework, parents' weakest performances are related to problem solving and tasks that involve mental calculus. They blame the new methodological approaches that are quite different from those they remember from the time when they were students. These difficulties felt by parents when they try to help their children with their mathematics homework are also pointed out in other studies (Jay et al., 2018).

In another study, Núñez et al. (2015) aim to understand the relationship that exists between parental involvement in students' homework, student homework behavioural patterns and student academic achievement. During his research work conducted with students from different school levels, the authors say "that students' homework behavioural patterns, perceived parental involvement in students' homework, and academic achievement are significantly related" (p. 375).

As far as homework is concerned, students, parents and teachers will build multiple interactions, clearly supported by their, sometimes divergent, visions that will influence their practices. This study will analyse this confluence of perceptions/visions and actions about the role played by homework in primary math education and about how that role is perceived by teachers, students and parents.

\section{Problem Statement}

This research aims to knowthe perspectives of pupils, of their parents/guardians and of teachers, regarding homework in the curricular area of mathematics and how they are implemented.

\section{Research Questions}

How is homework in the mathematics curricular area perceived by 4th year pupils, their parents/guardians and teachers, and how is this homework put into practice?

\section{Purpose of the Study}

In Portugal, as in many other countries of the world. homework is usually present in primary schools, namely in the area of mathematics. However, there is a lack of consensus regarding its educational value and it is relevant to know the perspective of its protagonists with concern to the contributions and difficulties of this pedagogical strategy. 


\section{Research Methods}

This research aims to identify the perspectives and practices of pupils and parents on the importance of the homework which is assigned by math teachers. Bearing in mind the purpose of the study, a mixed methods research was chosen because of the descriptive character it offers to the quantitative component and the interpretative character that can be useful to analyse the qualitative component.

For that purpose, multiple data collection techniques have been used to achieve greater data variety and breadth. In general terms, the study adopts an interpretative approach in order to understand how the object of the study is perceived by each participant involved.

\subsection{Participants and their characterization}

Students from two 4th grade classes of a school located in the central region of Portugal, four parents and two teachers participated in this study.

Twenty-four of the students surveyed $(\mathrm{N}=50)$ belong to class A and the other twenty-six to class B and the two groups are gender-balanced. Students from both classes are between 9 and 11 years old, and the vast majority of them are 9 year olds (only one of the students is 11 years old). The parents involved are students' mothers: three of them hold a college degree and one of them is a high school graduate. They are between 35 and 40 years old. One of them is 54 .

Those participants were chosen for the study because they were attending the school where, the year before, the first author of this paper did her traineeship to obtain the master's degree required for teaching in primary school. 4th graders (the last school year in the Portuguese primary level education) were chosen because it was a group who was likely to have some experience in dealing with homework. It was also thought to be important to hear the pupils' parents so as to understand their opinion about homework, that's why we interviewed four parents, two from each class (called Pi, with i ranging from 1 to 4). Finally, to understand what kind of homework students are talking about, we listened to the teachers' positions (who will be called Ti, with i ranging from 1 to 2 ) and asked them to inform us on a daily basis about the students' homework assignments. That information would cover a whole month and would concern every curricular área.

\subsection{Data collection techniques and tools}

To conduct this study, we chose to apply a questionnaire to all the students who were taking part in the study, to carry out an interview with each of the four parents and to conduct a documentary research.

The questionnaire, designed in accordance with the goals of this investigation presents two items covering the participants' demographic characteristics (gender and age) and seventeen items that will allow for the gathering of information about homework and that will rely on different types of survey questions: open-ended questions, closed-ended questions and multiple choice (Creswell, 2002).

The questions designed refer to the type of homework assigned, to the curricular areas with heavier homework loads, to the students' favourite areas, to the kind of help they get while doing their homework, among other issues. We chose to conduct a semi-structured interview with the four children's mothers because it is an in-depth technique that allows researchers to collect data directly and a means of interaction that allows the clarification of the questions asked and that can allow for classification and qualification 
procedures (Silverman, 2013). To conduct the interview, we developed a script that focused on students' homework and on the interaction parents establish with their children while helping them do their tasks, and particularly on the kind of difficulties experienced in supporting them.

In addition to the survey and to the interview, we also resorted to a documentary research of the teachers' records for each of the two classes in which they described the homework that they had assigned their students every day for a whole month.

\section{Findings}

In this section, we present and analyze the data obtained, according to three points: i) the scope and completion of homework by the students; ii) parent perspectives on homework; iii) homework requested by teachers.

\subsection{Homework scope and its completion by students}

The pupils from both classes signalled whether or not they are used to completing the homework they were assigned in the different curriculum areas. Emphasis is placed on mathematics (every student from both classes claims to have completed the tasks assigned) and then on Portuguese and Social and Environmental Education/Science (Table1). Arts Education is the area with lower values of homework completion (13\% and 18\%, respectively, in class A and B).

Table 01. Homework curriculum areas

\begin{tabular}{|l|c|c|c|c|}
\hline \multicolumn{1}{|c|}{ Curriculum areas } & \multicolumn{2}{c|}{ Class A } & \multicolumn{2}{c|}{ Class B } \\
\hline & N & $\%$ & N & 96 \\
\hline Portuguese & 22 & 92 & 25 & 100 \\
\hline Mathematics & 24 & 100 & 26 & 96 \\
\hline $\begin{array}{l}\text { Social and Environmental } \\
\text { Education/Science }\end{array}$ & 22 & 92 & 25 & 69 \\
\hline Arts Education & 3 & 13 & 18 & \\
\hline
\end{tabular}

The kind of homework that math teachers request the most is mathematical problems and numerical operations. In Portuguese classes, the type of homework that is more often requested, in both classes, corresponds to reading texts, looking words up in the dictionary, performing writing exercises (these two last tasks were referred by the students of class B only). The completion of non-specific worksheets is a very common task for both classes, with values around $90 \%$.

When we asked the students about the homework they prefer doing, evidence shows that the tasks assigned by their Social and Environmental Education/Science teachers are their favourite. Questioned about other types of homework they would like to be assigned, students pointed out group work tasks, research on the internet and carrying out surveys to their family. On the other hand, mathematics (Class A) and Portuguese (class B) are considered the worst areas for students as far as homework is concerned. Their justifications are that in mathematics "things are more difficult and complicated" and that in Portuguese "We have to write a lot, we have too much to do". 
Students claim they do their homework four or five times a week, that is, they complete their tasks almost on a daily basis. When we asked them if they are used to doing any other type of study activity besides the homework assigned by the teacher, most of the students from class A state that they study their multiplication tables (mathematics) and read (Portuguese) and the vast majority of the students from class B refer that they study the multiplication table (mathematics).

When questioned about the time, on average, they spend doing their homework every day, most of the students from both classes claim they spend up to 30 minutes and no student spends more than 2 hours doing his homework (Table 2).

Table 02. The average amount of time students spend doing their homework

\begin{tabular}{|l|c|c|c|c|}
\hline \multicolumn{1}{|c|}{$\begin{array}{c}\text { Amount of time spent, on } \\
\text { average, per day }\end{array}$} & \multicolumn{2}{|c|}{ Class A } & \multicolumn{2}{c|}{ Class B } \\
\hline & N & N & 19 & 73 \\
\hline Up to 30 minutes & 16 & 67 & 6 & 23 \\
\hline Between 30 minutes and 1 hour & 6 & 25 & 1 & 4 \\
\hline Between 1 and 2 hours & 2 & 8 & - & - \\
\hline More than 2 hours & - & - & & \\
\hline
\end{tabular}

Mathematics and Portuguese are the curricular areas in which students have greater difficulties to complete their homework. Portuguese is the subject where students from class A experience greater problems (67\%), while students from class B face greater difficulties in their math tasks $(65 \%)$. Arts Education is the area in which students experience fewer difficulties to complete their tasks (one student only) (Table 3 ).

Table 03. Curriculum areas in which students have greater difficulties to complete their homework

\begin{tabular}{|l|c|c|c|c|}
\hline \multicolumn{1}{|c|}{ Curriculum areas } & \multicolumn{2}{c|}{ Class A } & \multicolumn{2}{c|}{ Class B } \\
\hline & N & \% & 7 & 27 \\
\hline Portuguese & 16 & 67 & 17 & 65 \\
\hline Mathematics & 5 & 21 & 2 & 8 \\
\hline $\begin{array}{l}\text { Social and Environmental } \\
\text { Education }\end{array}$ & 2 & 8 & - & - \\
\hline Arts Education & 1 & 4 & & \\
\hline
\end{tabular}

When asked about the kind of support they get when they do their homework, about $43 \%$ of the students say they do not have any help. The percentage is even higher in class A. When they are helped, support comes generally from their mothers or their brothers.

In the end, students were asked to give their opinion on the importance they attach to homework. The overwhelming majority of students from the two classes consider that homework is important to improve their school results and to better understand the contents taught in the classes. No student considers homework to be a waste of time. 


\subsection{Parents' perspectives on homework}

The interviewed parents refer that their children do their homework regularly and believe that those tasks help them improve their learning and lead to better school results: "they are a support, they complete and help students absorb the school contents they are taught and when the time comes to show what they have learned, they are more prepared" (P3). Whenever students have homework to do, parents try to support them and help them complete that task even though "sometimes both parents and children are tired, but homework must be done" (P3).

Parents consider that, generally speaking, the amount of homework load assigned to their children is enough to fulfil the intended goals, however, in some other cases, they consider that their children's work load is too heavy especially when the tasks mean they have to work during the weekend: homework is "adequate for the school year they are attending" although there are "days when I think they have too many tasks to complete and we need a little more time to complete them" (P3 and P4). For parents, the weekly distribution of homework assignment varies considerably:

"He has homework to do six days a week, he has homework assignments for the weekend too" (P1) and "he brings homework two or three times a week, it depends on the weeks, he is often given assignments he has to complete during the weekend in addition to those he had already brought during the week" (P4).

The amount of time parents spend to complete their children's homework varies depending on the "school subject and on the contents they are studying" (P3), although most of them claim it takes them about half an hour: "It takes us about 30 minutes" (P2). They also stress that after completing their homework, their children still have time available for other activities because "we organize the time we have so that he can have time for other extra school activities" (P2) and "our time table is well planned. She knows that as soon as she gets home she has to do her homework to be allowed to play or carry out other activities" (P4).

All the parents who participated in the study consider that the amount of homework does not affect family activities: "We manage to have enough time for everything" (P1), "since they don't have too many tasks assigned and they don't have to attend too many school subjects, there is time for the family. I know that it will be different when he will enter middle school [year 5 and 6 in Portugal] and we will have to adjust our work schedule so that we can still manage to find time for school matters and family activities" (P4).

The parents we had the opportunity to interview usually assist their children in the completion of their homework. That way, they are willing to collaborate with the school and to contribute to their children's academic success. When asked whether or not they felt the need for the implementation of other types of homework activities, parents replied that, for the time being, they were satisfied with the ones requested since "the kind of homework that the teacher requires already helps them acquire the contents they are learning" (P1).

Parents refer that the curriculum area in which they feel their children need more support is math because "it is where he faces more problems", but also "because it is the school subject my son likes the most" (P2 and P3). They also state that the curriculum area in which they feel more insecure when time comes to help their children is once again mathematics "because of the changes that have occurred in the syllabus and because many things have changed since I left school" (P1). 
When they feel they cannot help their children with their homework, parents also adopt some strategies: they tell their children to ask their teacher to give them additional support in class or to explain the contents they had to use in the task assigned again or they choose to research, study the subject content and then explain it to the child "he doesn't have to do the exercise he was required and puts his doubt to the teacher "(P1); "I will search the right information and I will understand the content and I will try to make him understand it as well" (P2).

\subsection{Homework requested by the teachers}

For a month, the two teachers recorded every homework assignment they had asked students in their classes to fulfil (A and B). Data shows that homework is requested regularly by the Mathematic, Portuguese and Social and Environmental Education teachers of the two classes (in about half of the month working days). Mathematics is the school subject where there are more assignments.

The type of homework which is mostly requested by teachers, in mathematics are exercises ("write the 4, 7, 8, 9 multiplication tables and do a multiplication worksheet from your student book (T2); solve the following situations using multiplication by $0.1 ; 0.01 ; 0.001 "$ (T2)), problem solving exercises taken from the children's workbook and from worksheets that weren't completed in class ("problem situations in accordance with the contents that are being studied" (T1); "Carrying out a worksheet from the students' book" (T1). The exercises are mainly numerical calculations or the application of rules learned to new situations. In all cases, the teacher's intention with their homework assignments is to consolidate student knowledge and to exercise students' learning and logical thinking procedures.

\section{Conclusion}

The results of this study suggest that homework is a teaching strategy that still plays a relevant role in the practices of Portuguese Primary School teachers (1st cycle of Basic education) and has therefore an important impact on the daily life of students and families.

Homework is almost a daily routine, a fact that is clearly expressed in the monthly records kept by the two teachers. This result is in line with other studies that have been conducted (Cooper et al., 2006; Fan et al., 2017; Menezes et al., 2016).

The curriculum areas in which teachers request more homework are mathematics and Portuguese. However, Social and Environmental Education/Science is the subject which accounts for student preferences in both classes in terms of homework.

By opposition, the least preferred areas are mathematics and Portuguese. These results are in accordance with those presented by Costa, Cardoso, Lacerda, Lopes, \& Gomes (2016) in a study conducted with 4th graders from a group of schools located in the central region of Portugal.

The type of homework that is requested more often by math teachers is a kind of exercise in which students will have to apply mathematical procedures to help them consolidate the knowledge they have acquired. Carrying out exercises is the second type of activity that teachers request from their students. According to Menezes et al. (2016), most of these homework assignments are taken from the students' school book. However, students reveal that they would like to carry out another type of homework that would require doing research on the internet, applying surveys to their family and working in group. Those 
suggestions show a willingness to escape from routine situations and from a type of work process that is based purely on individual performance.

The study also allows us to infer that the students we interviewed consider that homework is important for their learning and will help improve their school results. They claim to spend, on average, up to 30 minutes a day doing the tasks required by their teachers. This perspective is in accordance with the results of the meta-analyses carried out by Cooper et al. (2006) and Fan et al. (2017) that show that the completion of homework can have a positive impact on the students ' school performance.

Most of the parents we interviewed also attach great importance to homework and to the role it plays in their children's learning process, in the consolidation of the knowledge acquired at school and in the development of individual working habits. These results are consistent with the studies conducted by Núñez et al. (2015) and Menezes et al. (2016). In these authors' perspective, parents' involvement in their children's education plays an important role and has a strong impact, in their opinion, both on the cognitive development of the child and on his school performance and achievement. Consequently, the majority of parents do their best to be involved and to help their children with the tasks they were assigned by their math teachers, even though, as stated by Menezes et al. (2016) and Jay et al. (2018), they sometimes find it difficult to keep that commitment because of the new contents that are being taught and of the methodologies that are currently being used and that are unlike everything they experienced when they were students.

In short, this study shows that homework is a reality for the students we have interviewed. It is clear that homework assignments are frequently requested by mathematics teachers. The use of homework, perhaps because it is an important part of school culture, is not called into question by parents and pupils, or by the teachers who assign them. Every teacher who requests his students to carry out a certain task, the students who complete those tasks and those who support the students' work at home believe that it deserves some credit and should be a complement to the work done at school.

\section{Acknowledgments}

This work is financed by national funds through FCT - Fundação para a Ciência e Tecnología, I.P., under the project UID/Multi/04016/2016. Furthermore, we would like to thank the Polytechnic Institute of Viseu and CI\&DETS for their support.

\section{References}

Aharoni, R. (2008). Aritmética para pais: Um livro para adultos sobre a matemática das crianças. Temas de Matemática. Lisboa: Gradiva.

Cooper, H. (2001). The battle over homework: Common ground administrators, teachers, and parents. California: Corwin Press.

Cooper, H., Robinson, J. C., \& Patall, E. A. (2006). Does homework improve academic achievement? A synthesis of research, 1987-2003. Review of Educational Research, 76(1), 1-62.

Costa, M., Cardoso, A. P., Lacerda, C., Lopes, A., \& Gomes, C. (2016). Homework in primary education from the perspective of teachers and pupils. Procedia - Social and Behavioral Sciences, 217, 139148. Retrieved from Doi: 10.1016/j.sbspro.2016.02.047

Creswell, J. W. (2002). Educational research: Planning, conducting, and evaluating quantitative (pp. 146166). Upper Saddle River, NJ: Prentice Hall. 
Epstein, J. L., \& Van Voorhis (2001). School, family, and community partnerships: Preparing educators and improving schools. Westview Press.

Fan, H., Xu, J., Cai, Z., He, J., \& Fan, X. (2017). Homework and students' achievement in math and science: A 30-year meta-analysis, 1986-2015. Educational Research Review, 20, 35-54.

Hagger, M. S., Sultan, S., Hardcastle, S. J., \& Chatzisarantis, N. L. (2015). Perceived autonomy support and autonomous motivation toward mathematics activities in educational and out-of-school contexts is related to mathematics homework behavior and attainment. Contemporary Educational Psychology, 41, 111-123.

Jay, T., Rose, J., \& Simmons, B. (2018). Why is parental involvement in children's mathematics learning hard? Parental perspectives on their role supporting children's learning. Sage Open, 8(2), Doi: 2158244018775466.

Marques, R. (2001). Educar com os pais. Lisboa: Editorial Presença.

Menezes, L., Viseu, F., \& Conceição, S. (2016). Ensino e aprendizagem da Matemática no contexto da implementação de um novo programa: os pais contam?. Revista Educação Matemática Pesquisa, 18(1), 131-152.

Núñez, J. C., Suárez, N., Rosário, P., Vallejo, G., Valle, A., \& Epstein, J. L. (2015). Relationships between perceived parental involvement in homework, student homework behaviors, and academic achievement: Differences among elementary, junior high, and high school students. Metacognition and learning, 10(3), 375-406. Doi: 10.1007/s11409-015-9135-5

Perrenoud, P. (2010). Métier d'élève et sens du travail (6th ed.). Paris: ESF.

Rønning, M. (2011). Who benefits from homework assignments? Economics of Education Review, 30(1), 55-64. Retrieved from Doi:10.1016/j.econedurev.2010.07.001

Sheldon, S. B., \& Epstein, J. L. (2005). Involvement counts: Family and community partnerships and mathematics achievement. The Journal of Educational Research, 98(4), 196-207.

Silva, R. (2009). Etapas processuais dos trabalhos de casa e efeitos autorregulatórios na aprendizagem do Inglês: Um estudo com diários de TPC no 2. ${ }^{\circ}$ Ciclo do Ensino Básico (Tese de doutoramento em educação), Instituto de Educação e Psicologia, Universidade do Minho, Braga.

Silverman, D. (2013). Doing qualitative research: A practical handbook. SAGE Publications Limited. 